CLINICAL STUDY

\title{
Absence of exercise-induced variations in adiponectin levels despite decreased abdominal adiposity and improved insulin sensitivity in type 2 diabetic men
}

\author{
P Boudou, E Sobngwi, F Mauvais-Jarvis, P Vexiau and J-F Gautier \\ Department of Hormonal Biology and Department of Endocrinology and Diabetes, Saint-Louis University Hospital, Assistance Publique - Hospitaux de \\ Paris, Paris, France
}

(Correspondence should be addressed to P Boudou; Email: philippe.boudou@sls.ap-hop-paris.fr)

\begin{abstract}
Objective: We investigated the effect of an intensive training program on fasting leptin and adiponectin levels.

Methods: Sixteen middle-aged men with type 2 diabetes were randomly assigned to either a training or control group. The training program consisted of 8 weeks of supervised endurance exercise $(75 \%$ $\mathrm{VO}_{2 \text { peak }}, 45 \mathrm{~min}$ ) twice a week, with intermittent exercise (five $2 \mathrm{~min}$ exercises at $85 \% \mathrm{VO}_{2 \text { peak }}$ separated by 3 min exercises at $50 \% \mathrm{VO}_{2 \text { peak }}$ ) once a week, on an ergocycle.

Results: Training decreased abdominal fat by $44 \%$, increased mid-thigh muscle cross-sectional area by $24 \%$, and improved insulin sensitivity by $58 \%$ without significant change in body weight. Compared with controls, no significant variation in leptin or adiponectin levels was observed. However, in the trained group, change in adiponectin correlated with change in body weight (Spearman rank correlation, $r_{\mathrm{s}}:-0.76, P=0.03$ ) but not with insulin sensitivity or abdominal adiposity variations.

Conclusions: An 8 week intensive training program inducing a marked reduction in abdominal fat and increase in insulin sensitivity does not affect adiponectin and leptin levels in men with type 2 diabetes.
\end{abstract}

European Journal of Endocrinology 149 421-424

\section{Introduction}

Circulating leptin levels are correlated with body weight and more specifically with total body fat in humans and decline in subjects following weight loss (1). By contrast, adiponectin concentrations are lower in obese subjects (2), type 2 diabetic patients (3) and patients with coronary artery disease (3) compared with healthy controls, and increase after weight loss (4). Both adipocytokines are related to insulin action $(5,6)$. Exercise training improves insulin sensitivity (7) and body fat (8), but to date, the effect of exercise training on adiponectin levels in diabetic patients has not been investigated. We have previously reported that an intensive supervised training program improves insulin sensitivity and decreases visceral and subcutaneous adipose tissue in middle-aged type 2 diabetic males (9). In the present report, we analyzed the effects of this program on circulating adiponectin levels in relation to abdominal fat and insulin sensitivity in type 2 diabetic men.

\section{Patients and methods}

Sixteen type 2 diabetic men (known duration $<10$ years) aged $45.4 \pm 7.2 \quad$ (s.D.) with glycosylated hemoglobin of $8.1 \pm 1.7 \%$ and stable body mass index (BMI, $29.6 \pm 4.6 \mathrm{~kg} / \mathrm{m}^{2}$ ), reporting no participation in regular exercise for at least 6 months prior to inclusion, were recruited and randomly assigned to an eight-subject training group and an eight-subject control group. A randomized list was generated using the SAS program (SAS Institute, Cary, NC, USA). The trained group was assigned to an 8 week training program (three times/week) consisting of two different kinds of exercise: first, a continuous exercise for $45 \mathrm{~min}$ at $75 \%$ of their $\mathrm{VO}_{2 \text { peak }}$ twice a week; secondly, an intermittent exercise, once a week, consisting of five exercises at $85 \% \mathrm{VO}_{2 \text { peak }}$ for $2 \mathrm{~min}$ separated by $3 \mathrm{~min}$ exercise at $50 \% \mathrm{VO}_{2 \text { peak }}$. The control subjects were seen weekly to exercise on the bicycle ergometer at a constant rate of 60 r.p.m. for $20 \mathrm{~min}$ at low intensity $(30 \mathrm{~W})$. All subjects had been followed in our department for at least 1 year, 
and were asked to maintain their usual diet corresponding in all cases to approximately 50\% carbohydrates, $30 \%$ lipids and $20 \%$ proteins. Daily caloric intake was estimated based on the assumption that resting metabolic rate represents $70 \%$ of total energy expenditure. After a $30 \mathrm{~min}$ rest period, post-absorptive metabolic rate was measured for $30 \mathrm{~min}$ by indirect calorimetry (Sensor Medics 2900, Sensor Medics Corporation, Yorba Linda, CA, USA).

Before enrollment and at the end of the training program (3-5 days after the last exercise session), all subjects underwent an assessment of food diaries, evaluation of the level of physical activity (Baecke's questionnaire), anthropometric measurements (weight to $0.1 \mathrm{~kg}$, height to $0.5 \mathrm{~cm}$, BMI in $\mathrm{kg} / \mathrm{m}^{2}$ ), abdominal fat distribution using magnetic resonance imaging (MRMax; General Electric, Milwaukee, WI, USA) at the level of the umbilicus $\left(\mathrm{L}_{4}-\mathrm{L}_{5}\right)$, as previously described with a $2 \%$ coefficient of variation (CV) (9). After a $12 \mathrm{~h}$ overnight fast, insulin sensitivity was evaluated by an i.v. insulin-tolerance test (ITT) performed after discontinuation of hypoglycemic medication, if any, either in the morning (sulfonylureas) or $48 \mathrm{~h}$ before (metformin) the beginning of the test. Five patients (two in the trained and three in the untrained group) were free of medication over the whole study. Six patients (two in the trained and four in the untrained group) were taking metformin alone and five (four in the trained and one in the untrained group) were taking a combination of metformin and gliclazide or glibenclamide. No change in hypoglycemic treatment was performed during the study period. Leptin and adiponectin levels (intra-assay $\mathrm{CV}=3.5-5.0 \%$ ) were determined prior to the ITT by RIA (Linco Research Inc., St Charles, MO, USA). All the samples were run in duplicate in the same batch.

The local Ethics Committee approved this investigation, and informed consent was obtained from all patients.
Results are expressed as means \pm S.D. Changes in leptin and adiponectin levels between the trained and the control group were compared using the MannWhitney U test. The association between these variables was assessed by Spearman rank correlation $\left(r_{\mathrm{s}}\right)$. Within-group comparisons were performed using the non-parametric Wilcoxon matched-pairs signedrank test.

\section{Results}

Mean energy intake was similar in all groups, and except for the ergocycle exercise, physical activity remained unaffected. Resting metabolic rate before and after the training period was $1680 \pm 307$ vs $1716 \pm 327 \mathrm{kcal} /$ day in the control group, and $1582 \pm 300$ vs $1613 \pm 313 \mathrm{kcal} /$ day in the trained group (NS). Pre- and post-training characteristics of both groups are reported in Table 1. Although body weight was not modified by exercise training, visceral fat and subcutaneous abdominal fat significantly decreased by 44 and $18 \%$ respectively, while midthigh muscle cross-sectional area significantly increased by $24 \%$ and insulin sensitivity improved by $58 \%$ (Table 1).

Percent changes in adiponectin levels correlated with percent decrease in body weight $\left(r_{\mathrm{s}}=0.76, P=0.03\right)$. Changes in leptin and adiponectin levels were inversely correlated $\left(r_{\mathrm{s}}=-0.67, P=0.07\right)$. Following exercise training, decrease in visceral or subcutaneous adipose tissue areas and improvement in insulin sensitivity were not significantly correlated with changes in adiponectin levels (Fig. 1). However, seven of eight trained subjects $(88 \%)$ improved their insulin sensitivity by $13-106 \%$ (range), and five of these seven subjects (70\%) decreased their adiponectin levels by $20-57 \%$ (range) (Fig. 2). By contrast, in the control group, five of eight subjects (63\%) did not change their

Table 1 Anthropometric and biological parameters of the trained $(n=8)$ and control $(n=8)$ groups before and after the study period. Results expressed as means \pm S.D.

\begin{tabular}{|c|c|c|c|c|}
\hline & \multicolumn{2}{|c|}{ Trained group } & \multicolumn{2}{|c|}{ Control group } \\
\hline & Before & After & Before & After \\
\hline Age (years) & $42.90 \pm 5.20$ & - & $47.90 \pm 8.35$ & - \\
\hline Body weight (kg) & $86.90 \pm 13.40$ & $85.00 \pm 13.75$ & $90.40 \pm 11.50$ & $88.75 \pm 11.30$ \\
\hline BMI $\left(\mathrm{kg} / \mathrm{m}^{2}\right)$ & $28.30 \pm 3.90$ & $27.60 \pm 4.30$ & $30.85 \pm 5.20$ & $30.35 \pm 5.20$ \\
\hline Visceral adipose tissue $\left(\mathrm{cm}^{2}\right)$ & $153.25 \pm 38.55$ & $84.20 \pm 21.30^{*}$ & $156.85 \pm 23.40$ & $150.35 \pm 23.25$ \\
\hline Subcutaneous adipose tissue $\left(\mathrm{cm}^{2}\right)$ & $241.55 \pm 49.55$ & $198.00 \pm 39.00^{*}$ & $262.50 \pm 69.10$ & $260.00 \pm 70.40$ \\
\hline Mid-thigh muscle cross-sectional area $\left(\mathrm{cm}^{2}\right)$ & $148.30 \pm 36.10$ & $184.35 \pm 35.85^{\star}$ & $157.40 \pm 43.20$ & $151.40 \pm 44.70$ \\
\hline Glycemia $(\mathrm{mmol} / \mathrm{l})$ & $9.35 \pm 1.20$ & $9.70 \pm 1.65$ & $8.50 \pm 2.15$ & $8.55 \pm 1.95$ \\
\hline Insulinemia (mU/l) & $21.30 \pm 7.25$ & $22.35 \pm 8.20$ & $21.60 \pm 7.65$ & $24.30 \pm 14.00$ \\
\hline Leptin $(\mu \mathrm{g} / \mathrm{l})$ & $6.05 \pm 4.60$ & $5.60 \pm 4.30$ & $7.26 \pm 3.85$ & $7.40 \pm 3.95$ \\
\hline Adiponectin $(\mu \mathrm{g} / \mathrm{ml})$ & $6.30 \pm 2.75$ & $6.00 \pm 3.50$ & $7.30 \pm 2.55$ & $7.05 \pm 2.10$ \\
\hline $\mathrm{K}_{\mathrm{ITT}}(\% / \mathrm{min})$ & $2.15 \pm 0.65$ & $3.25 \pm 0.85^{\star *}$ & $1.95 \pm 1.00$ & $1.80 \pm 0.90$ \\
\hline
\end{tabular}

${ }^{*} P<0.001,{ }^{* *} P<0.02$ after/before values in the trained vs control group.

$\mathrm{K}_{\mathrm{ITT}}$, constant rate of plasma glucose disappearance during the ITT. 

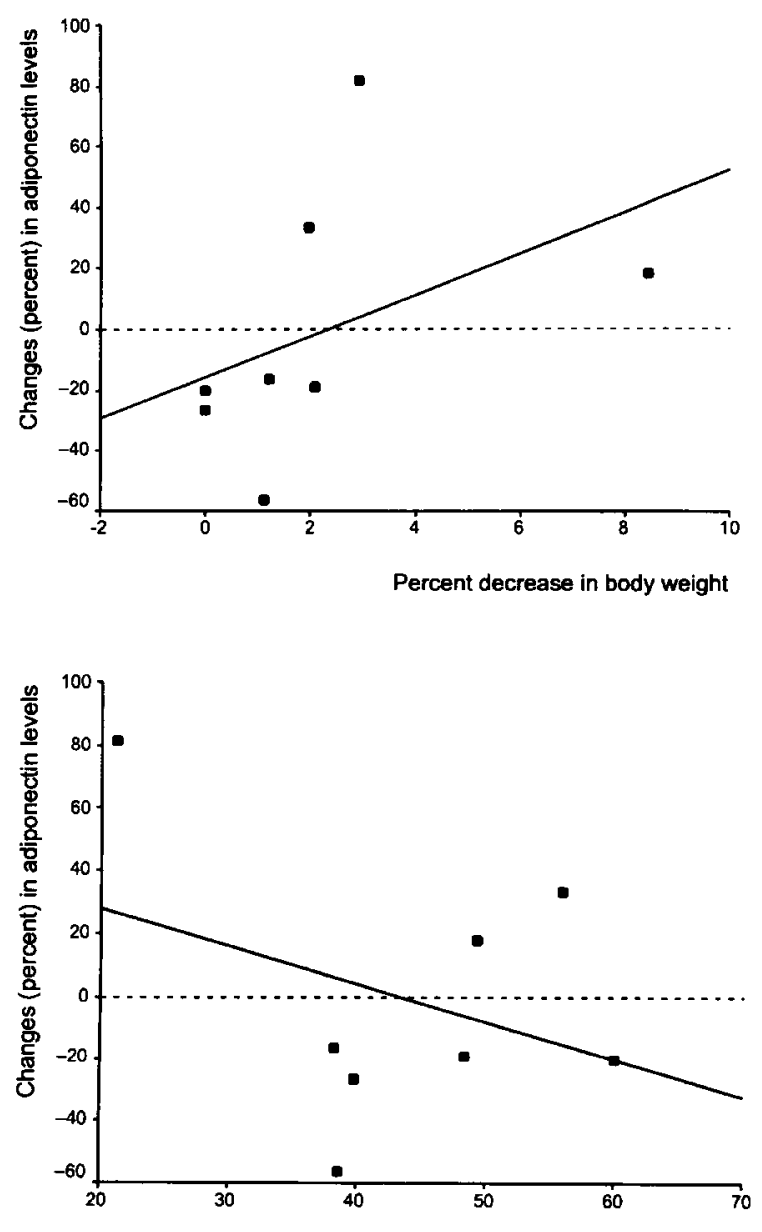

Percent decrease in visceral adipose tissue

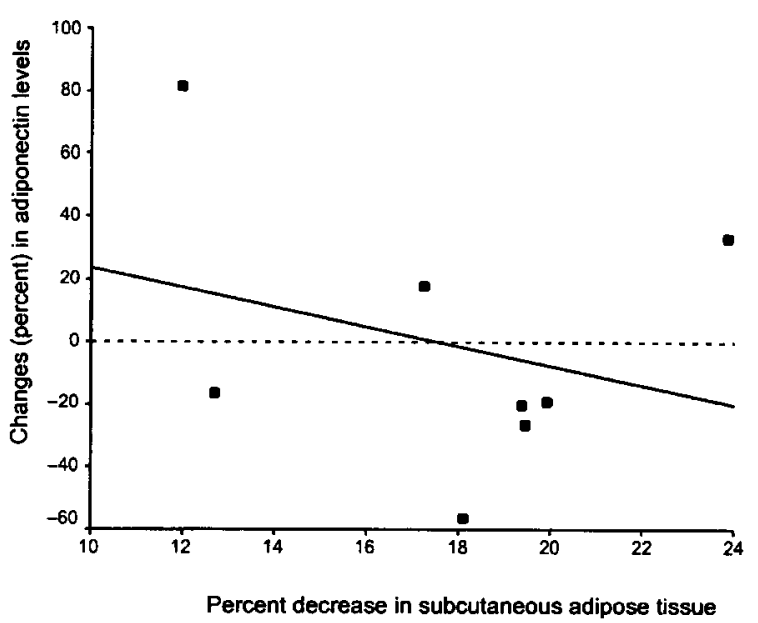

Figure 1 Relationship between percent changes in adiponectin levels and (upper panel) percent decrease in body weight $\left(r_{\mathrm{s}}=0.76, P=0.03\right)$, (middle panel) percent decrease in visceral adipose tissue $\left(r_{\mathrm{s}}=-0.09, P=0.82\right)$, and (lower panel) percent decrease in subcutaneous adipose tissue $\left(r_{\mathrm{s}}=-0.26\right.$, $P=0.53$ ) following 8 weeks of exercise training. The dashed line represents the reference line for unchanged adiponectin levels.

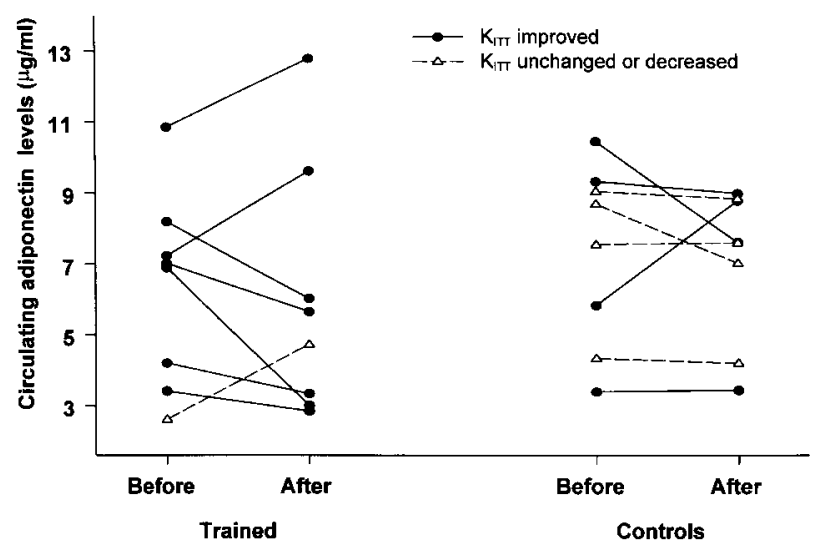

Figure 2 Individual variations in adiponectin levels (at baseline and after the 8 week training program) in the trained and the control group, in subjects with improved and with unchanged or decreased insulin sensitivity. $\mathrm{K}_{\mathrm{ITT}}$, constant rate of plasma glucose disappearance during the ITT.

adiponectin levels. Individual variation of adiponectin levels in trained and control groups according to insulin sensitivity changes are shown in Fig. 2.

\section{Discussion}

Our data show that a supervised intensive training program did not induce significant changes in adiponectin and leptin levels despite a tremendous decrease in abdominal fat and improvement in insulin sensitivity in sedentary middle-aged type 2 diabetic men maintaining their usual dietary habits.

Due to reduced sample size and possible heterogeneity of the study population with regard to age, body weight, hypoglycemic treatment and diabetes control at baseline, we focused mainly on the individual variations of the defined target variables over the study period.

There is some evidence from the literature that only reductions in body weight above the threshold of $10 \%$ are likely to result in a significant decrease in circulating leptin levels $(1,10,11)$. Such a threshold effect is likely to also apply to adiponectin variations, since an increase in circulating adiponectin levels has been reported in obese patients following a weight loss of $10 \%$ or more consecutive to restrictive diet or gastric banding $(3,12)$. This magnitude of weight loss was not achieved in our study $(2.2 \%$ weight loss $)$, probably because the reduction in visceral adiposity was balanced by the increase in muscle mass. The marked reduction in abdominal adipose tissue induced by our training program was not associated with crude increase in adiponectin levels. However, we found an inverse relationship between changes in body weight and changes in adiponectin levels in the trained group. 
According to Tataranni's group $(6,13)$, hypoadiponectinemia is more closely related to insulin resistance than adiposity. In the present study, the tremendous improvement in insulin sensitivity in the trained group was not associated with a significant change in adiponectin and leptin levels. These results are unlikely to be explained by hypoglycemic medications among the groups since no significant change in adiponectin levels are reported in patients taking metformin (14). With the exception of the study by Perusse et al. (15), other exercise training protocols did not affect leptin (16) or adiponectin levels (12).

Exercise improves insulin sensitivity at least in part through AMP kinase pathway activation (17). It has recently been shown that adiponectin also increases muscular insulin sensitivity through the same pathway (18). Thus elevation of adiponectin levels may no longer be necessary to increase insulin sensitivity during exercise training. Contrasting with diet-induced weight loss, the improvement of insulin sensitivity by training is not related to adiponectin variations.

In conclusion, despite a decrease in abdominal adiposity and improvement in insulin sensitivity, an 8 week intensive training program did not significantly affect fasting leptin and adiponectin levels, suggesting the absence of a direct cause-effect relationship between adiposity, insulin sensitivity and these adipocytokines.

\section{Acknowledgements}

The assistance of Raphaël Porcher (Department of Biostatistics and Medical Informatics) is gratefully acknowledged.

\section{References}

1 Considine RV, Sinha MK, Heiman ML, Kriauciunas A, Stephens TW, Nyce MR et al. Serum immunoreactive-leptin concentrations in normal-weight and obese humans. New England Journal of Medicine $1996334292-295$.

2 Arita Y, Kihara S, Ouchi N, Takahashi M, Maeda K, Miyagawa J et al. Paradoxical decrease of an adipose-specific protein, adiponectin, in obesity. Biochemical and Biophysical Research Communications 1999257 79-83.

3 Hotta K, Funahashi T, Arita Y, Takahashi M, Matsuda M, Okamoto Yet al. Plasma concentrations of a novel, adipose-specific protein, adiponectin, in type 2 diabetic patients. Arteriosclerosis, Thrombosis, and Vascular Biology 200020 1595-1599.

4 Yang WS, Lee WJ, Funahashi T, Tanaka S, Matsuzawa Y, Chao CL et al. Weight reduction increases plasma levels of an adiposederived anti-inflammatory protein, adiponectin. Journal of Clinical Endocrinology and Metabolism 200186 3815-3819.

5 Kennedy A, Gettys TW, Watson P, Wallace P, Ganaway E, Pan Q et al. The metabolic significance of leptin in humans: gender-based differences in relationship to adiposity, insulin sensitivity, and energy expenditure. Journal of Clinical Endocrinology and Metabolism 199782 1293-1300.

6 Weyer C, Funahashi T, Tanaka S, Hotta K, Matsuzawa Y, Pratley RE et al. Hypoadiponectinemia in obesity and type 2 diabetes: close association with insulin resistance and hyperinsulinemia. Journal of Clinical Endocrinology and Metabolism $2001 \mathbf{8 6}$ 1930-1935.

7 Bogardus C, Ravussin E, Robbins DC, Wolfe RR, Horton ES \& Sims EA. Effects of physical training and diet therapy on carbohydrate metabolism in patients with glucose intolerance and non-insulin-dependent diabetes mellitus. Diabetes 198433 311-318.

8 Lehmann R, Vokac A, Niedermann K, Agosti K \& Spinas GA. Loss of abdominal fat and improvement of the cardiovascular risk profile by regular moderate exercise training in patients with NIDDM. Diabetologia 199538 1313-1319.

9 Mourier A, Gautier JF, De Kerviler E, Bigard AX, Villette JM, Garnier JP et al. Mobilization of visceral adipose tissue related to the improvement in insulin sensitivity in response to physical training in NIDDM. Effects of branched-chain amino acid supplements. Diabetes Care 199720 385-391.

10 Rosenbaum M, Nicolson M, Hirsch J, Murphy E, Chu F \& Leibel RL. Effects of weight change on plasma leptin concentrations and energy expenditure. Journal of Clinical Endocrinology and Metabolism 199782 3647-3654.

11 Hulver M \& Houmard J. Plasma leptin and exercise: recent findings. Sports Medicine 200333 473-482.

12 Hulver MW, Zheng D, Tanner CJ, Houmard JA, Kraus WE, Slentz CA et al. Adiponectin is not altered with exercise training despite enhanced insulin action. American Journal of Physiology. Endocrinology and Metabolism 2002283 E861-E865.

13 Stefan N, Vozarova B, Funahashi T, Matsuzawa Y, Weyer C, Lindsay RS et al. Plasma adiponectin concentration is associated with skeletal muscle insulin receptor tyrosine phosphorylation, and low plasma concentration precedes a decrease in wholebody insulin sensitivity in humans. Diabetes $2002 \mathbf{5 1}$ 1884-1888.

14 Phillips SA, Ciaraldi TP, Kong AP, Bandukwala R, Aroda V, Carter L et al. Modulation of circulating and adipose tissue adiponectin levels by antidiabetic therapy. Diabetes $2003 \mathbf{5 2}$ 667-674.

15 Perusse L, Collier G, Gagnon J, Leon AS, Rao DC, Skinner JS et al. Acute and chronic effects of exercise on leptin levels in humans. Journal of Applied Physiology 199783 5-10.

16 Hickey MS, Houmard JA, Considine RV, Tyndall GL, Midgette JB, Gavigan KE et al. Gender-dependent effects of exercise training on serum leptin levels in humans. American Journal of Physiology 1997272 E562-E566.

17 Musi N, Fujii N, Hirshman MF, Ekberg I, Froberg S, Ljungqvist O et al. AMP-activated protein kinase (AMPK) is activated in muscle of subjects with type 2 diabetes during exercise. Diabetes 200150 921-927.

18 Yamauchi T, Kamon J, Minokoshi Y, Ito Y, Waki H, Uchida S et al. Adiponectin stimulates glucose utilization and fatty-acid oxidation by activating AMP-activated protein kinase. Nature Medicine 20028 1288-1295.

Received 14 April 2003

Accepted 29 July 2003 